\title{
THE RELATIONSHIP BETWEEN TLICS 1-3 AND FUNCTIONAL AND RADIOLOGICAL OUTCOMES IN CONSERVATIVE TREATMENT OF THORACOLUMBAR VERTEBRAE FRACTURES
}

\author{
(1) Evren Karaali', (1) Fırat Seyfettinoğlu1', (1) Osman Çiloğlu', (1) Altuğ Duramaz², (1) Gökhan Peker3, \\ (1) Mehmet İnce' ${ }^{1}$, (1) Hüseyin Mehmet Gürbüz
}

\author{
${ }^{1}$ University of Health Sciences Turkey, Adana City Training and Research Hospital, Clinic of Orthopedics and Traumatology, Adana, Turkey \\ 2University of Health Sciences Turkey, Bakırköy Dr. Sadi Konuk Training and Research Hospital, Clinic of Orthopedics and Traumatology, \\ Istanbul, Turkey \\ ${ }^{3}$ University of Health Sciences Turkey, Trabzon Kanuni Training and Research Hospital, Clinic of Orthopedics and Traumatology, Trabzon, Turkey
}

\begin{abstract}
Objective: There is almost no controversy about the conservative treatment of patients with fractures with a Thoracolumbar injury classification and severity score (TLICS) of 1-3. External thoracolumbosacral orthosis is the recommended method. However, it is still controversial to support the TLICS with radiological parameters. The aim of this study was to evaluate the correlation between TLICS scores of 1-3 and clinical and radiological results of patients with stable thoracolumbar and lumbar vertebrae fractures, who were followed up conservatively.

Materials and Methods: This retrospective study included patients diagnosed as having TLICS 1 to 3 thoracolumbar or lumbar vertebrae fractures who were followed up conservatively. Data were gained from the patient files. Outcome measures and classification parameters used were; visual analogue scale (VAS) and Turkish version of Oswestry disability index (ODI). The radiological parameters were measured. The recovery rates of all patients were evaluated, and correlation between clinical and radiological outcomes of the patients and TLICS scores was analyzed.

Results: The mean duration of hospitalization and time to return to work were 1.61 and 126 days, respectively. Both VAS and ODI values steadily decreased over time. However, local kyphotic angle (LKA) and vertebra height loss (VHL) percentage values increased over time. TLICS did not correlate with the time to return to work. However, LKA at admission and VHL percentage at admission correlated significantly with the time to return to work.

Conclusion: The TLICS classification seems to be effective in decision making in the conservative treatment of thoracolumbar and lumbar vertebral fractures, but it would be noteworthy to take into account the clinical and radiological parameters in this classification to predict the treatment period and time to return to work.
\end{abstract}

Keywords: TLICS, thoracolumbosacral orthosis, vertebrae fracture, conservative treatment

\section{INTRODUCTION}

The conservative approach is the generally accepted treatment method in stable thoracolumbar and lumbar fractures ${ }^{(1-5)}$. In this sense, an external thoracolumbosacral orthosis (TLSO) is recommended according to the level of injury ${ }^{(1,2)}$. Herewith, in recent years, the thoracolumbar injury classification and severity score (TLICS) have been frequently used to determine management ${ }^{(2,4,6-8)}$ (Table 1). There is almost no controversy about the conservative treatment of TLICS 1-3 fractures and operative treatment of TLICS $\geqslant 5$ fractures, whereas TLICS 4 is controversial(2,8-11). However, the lack of predicting radiological progress and time to return to work are the main challenges of TLICS. For instance, the progressive kyphotic deformity was shown in comminuted burst fractures with a TLICS score of 2 treated non-operatively ${ }^{(12)}$. Moreover, it has been suggested that worsening radiographic findings are associated with an increase in the incidence of permanent pain ${ }^{(4,11)}$. There are also studies showing no correlation between the local kyphosis angle (LKA) and vertebral height loss (VHL) and clinical results. From this point of view, it was claimed that radiological parameters should be excluded from the TLICS(13). However, it is still controversial to support the TLICS with radiological 
Table 1. Thoracolumbar injury classification and severity score (TLICS)

\begin{tabular}{ll}
\hline Morphology & \\
\hline Compression fracture & 1 point \\
Burst fracture & 2 points \\
Translation/rotation & 3 points \\
Distraction & 4 points \\
\hline Posterior ligamentous complex & \\
\hline Intact & 0 points \\
Suspected injury or indeterminate & 2 points \\
Injured & 3 points \\
\hline Neurologic involvement & \\
\hline Intact & 0 points \\
Nerve root & 2 points \\
Cord/conus medullaris (incomplete) & 3 points \\
Cord/conus medullaris (complete) & 2 points \\
Cauda equine & 3 points \\
\hline 1-3:Usuly &
\end{tabular}

1-3: Usually treated non-operatively, 4: May be treated operatively or non-operatively, $\geqslant 5$ : Usually considered for operative management TLICS: Thoracolumbar injury classification and severity score

parameters ${ }^{(8,10,13,14)}$. Based on our experience, although TLICS is an effective method to choose the treatment method, it is still insufficient in predicting radiological changes and returning to work. Therefore, we aimed to evaluate the correlation between TLICS scores (1 to 3 ) and clinical and radiological results of patients with stable thoracolumbar and lumbar vertebrae fractures, who were followed up conservatively.

\section{MATERIALS AND METHODS}

\section{Study Design and Participants}

This retrospective study was conducted after the approval of the Clinical Research Ethics Committee. Between January 2013 and December 2017, the patients diagnosed with TLICS 1 to 3 thoracolumbar or lumbar vertebrae fractures, and who followed up conservatively in a tertiary hospital were enrolled. Inclusion criteria were; traumatic thoracolumbar and lumbar fractures (compression and burst) between T11-L5, only score of TLICS 1 to 3, without neurologic deficit, age at 18 to 65 years, within 24 hours of presentation and a minimum 24 months of followup period. Exclusion criteria were other TLICS scores such as $\geqslant 4$, patients with follow-up period of less than 24 months, pregnancy, having pathological fractures (cancer, infection) or osteoporotic fractures, previous history of spine surgery, and any missing data regarding the fracture. The patients were divided into three groups according to the scores obtained in TLICS classification. The recovery rates of all patients were evaluated, and the correlation between clinical and radiological outcomes of the patients and TLICS scores were compared. Informed consent was obtained from the patients.

\section{Treatment Method}

Patients were hospitalized for observation a minimum of 24 hours after diagnosis. Bed rest in a supine position, analgesic, and subcutaneous anticoagulant (enoxaparin sodium 40 $\mathrm{mg}=4000$ anti-Xa IU) therapy was administered. All patients were encouraged to be mobilized with a TLSO (Biofix ${ }^{\circledR}$ BA287) one day after the hospitalization. After discharge, the patients after were advised to comply with bed rest (at nights in supine position), to use TLSO (in sitting and standing position), anticoagulant therapy, and analgesic drugs. All patients were examined clinically with 2 weeks of intervals and radiologically 4 weeks of intervals, for 12 weeks. Thereafter, the follow-up was continued three months of intervals for 24 months.

\section{Data Collection and Radiographic Evaluation}

The data were obtained from the medical records of the patients. Clinical and demographic features (age, gender, level of fracture, and return to work) were noted. All patients had images of the two-plan radiograph, computed tomography scan, and magnetic resonance imaging on admission. Angular measurements were performed on the lateral spine radiographs at the first admission and at the final follow-up. LKA was measured as the angle from the superior end-plate to the inferior end-plate ${ }^{(13)}$. Normalized VHL was calculated as a percentage of the height loss normalized to the average of the vertebral bodies above and below the injured segment ${ }^{(13)}$. Radiographic evaluations were performed by a blinded senior spine surgeon.

\section{Outcome Measures}

The primary functional outcome measure was the oswestry disability index (ODI) that was validated for the Turkish population $^{(15)}$. The ODI is a functional, disease-specific instrument comprising ten questions on limitations in the activities of daily living, caused by low back pain. Each question is scored 0 to 5 . The ODI score is multiplied by two to acquire the percentage. The total score ranges 0 (best health state) to 100 (worst health state).

Secondary outcome measures included back pain visual analogue scale $(\mathrm{VAS})^{(16)}$ score, and time for the return to work. Records of VAS scores for back pain were collected and compared between the groups. VAS is a well-known, validated instrument to let patients score their daily pain. We used a 0 to 10 scale as scored $0=$ no pain and $10=$ unbearable pain. Time for a return to work was determined from self-reported at last follow-up time.

\section{Statistical Analysis}

SPSS software package program (SPSS Inc., version 16, Chicago, IL, USA) was used for statistical analysis. Descriptive data were given as mean, standard deviation, median, number, or percentage. Baseline and after-surgery data were compared using the Paired t-test or Wilcoxon signed-rank test. Pearson correlation analyses were performed for the correlation analyses. A value of $p<0.05$ was accepted as statistically significant. In the calculation of the post hoc sample size, the power of the study with 0.05 alpha value was found over $80 \%$. The standard effect size for quantitative data was set at $0.81 \%$, and the power of the study was $99 \%$. 


\section{RESULTS}

This study included a total of 153 patients (102 males, 51 females) with a mean age of $44.50 \pm 13.3$ years (ranges 18 to 65 years). Clinical and demographic properties of the patients are summarized in Table 2. Seventy-five patients (49.0\%), 71 patients (46.4\%), and 7 patients (4.6\%) patients were scored as TLICS 1, 2, and 3, respectively. The mean duration of hospitalization and time for the return to work was 1.61 and 126 days, respectively. The mean VAS score at admission was $8.29 \pm 1.1$, and the mean ODI was $21.38 \pm 8.1$ at the $3^{\text {rd }}$ month. Both VAS and ODI values steadily decreased over time (Figure 1 ). However, LKA and VHL values increased over time (Figure 2). The mean LKA increased from $26.75 \pm 6.7$ to $30.80 \pm 6.9(p<0.001)$. The mean VHL increased from $39.84 \pm 8.7$ to $47.81 \pm 8.6$. Correlation analyses are shown in Table 3. TLICS did not correlate with the time for the return to work $(r=0.124, p=0.127)$. However, LKA at admission $(r=0.427, p<0.001)$ and $\mathrm{VHL}$ at admission $(r=0.254$, $p=0.002$ ) correlated significantly with the time for the return to work. As the LKA or VHL increased, time for the return to work did prolong. Similarly, the VAS scores $(r=0.288, p<0.001)$ and $O D I$ values $(r=0.167, p=0.039)$ significantly correlated with the time for the return to work.

\section{DISCUSSION}

The purpose of this study was to evaluate the relationship between TLICS scores (1 to 3 ) and clinical and radiological outcomes of patients with stable thoracolumbar and lumbar vertebrae fractures and treated conservatively. Three main findings emerged from this study. First, the conservative treatment showed satisfactory outcomes. ODI and VAS scores values steadily decreased over time and significantly correlated with the time for the return to work. Second, both LKA and VHL values increased over time and were associated with prolonged

VAS

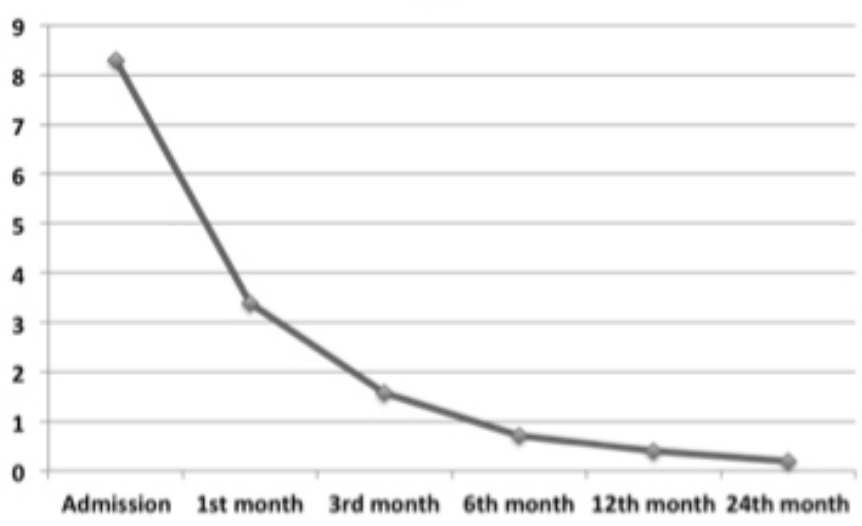

Table 2. Descriptive features of the patients

\begin{tabular}{|c|c|}
\hline & Mean \pm SD or $\mathbf{N}(\%)$ \\
\hline Age (years) & $\begin{array}{l}44.50 \pm 13.3 \\
46(18-65)\end{array}$ \\
\hline \multicolumn{2}{|l|}{ Gender } \\
\hline Male & $102(66.7)$ \\
\hline Female & $51(33.3)$ \\
\hline \multicolumn{2}{|l|}{ Fracture Region } \\
\hline Thoracolumbar & $131(85.6)$ \\
\hline Lumbar & $22(14.4)$ \\
\hline \multicolumn{2}{|l|}{ Level of Fracture } \\
\hline T11 & $5(3.3)$ \\
\hline T12 & $38(24.8)$ \\
\hline L1 & $48(31.4)$ \\
\hline L2 & $41(26.8)$ \\
\hline L3 & $7(4.6)$ \\
\hline L4 & $10(6.5)$ \\
\hline L5 & $4(2.6)$ \\
\hline \multicolumn{2}{|l|}{ Trauma Type } \\
\hline Fall from height & 58 (37.9) \\
\hline Basic falls & $14(9.2)$ \\
\hline In-vehicle traffic accident & $48(31.4)$ \\
\hline Out-vehicle traffic accident & $33(21.6)$ \\
\hline \multicolumn{2}{|l|}{ TLICS } \\
\hline 1 & $75(49.0)$ \\
\hline 2 & $71(46.4)$ \\
\hline 3 & $7(4.6)$ \\
\hline \multirow{2}{*}{ Hospitalization (days) } & $1.61 \pm 0.8$ \\
\hline & $2(1-7)$ \\
\hline \multirow{2}{*}{ Return to work (days) } & $130 \pm 20$ \\
\hline & $126(90-180)$ \\
\hline $\begin{array}{l}\text { SD: Standard deviation, TLICS: } 7 \\
\text { severity score }\end{array}$ & lumbar injury classificatic \\
\hline
\end{tabular}

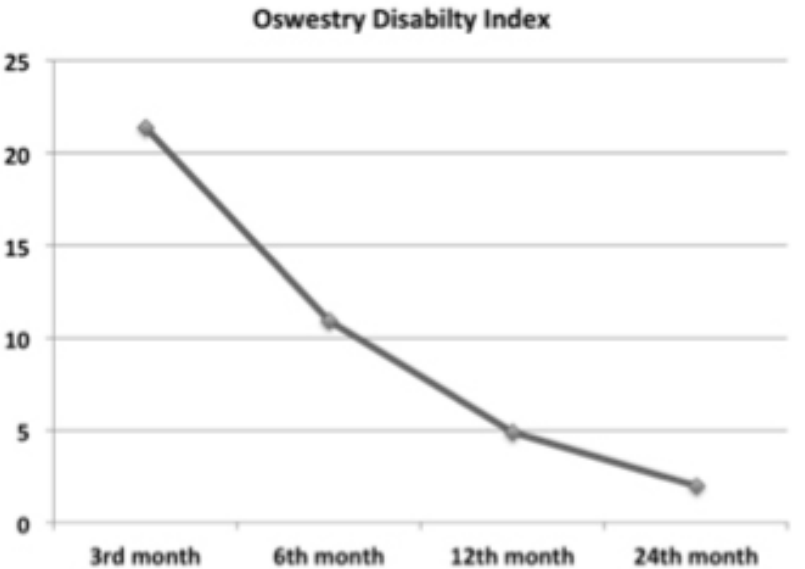

Figure 1. Visual analogue scale pain scores and Oswestry disability index values

The mean VAS score at admission was $8.29 \pm 1.1$ and the mean ODI was $21.38 \pm 8.1$ at the $3^{\text {rd }}$ month. Both VAS and ODI values steadily decreased over time.

VAS: Visual analogue scale; ODI: Oswestry disability index 
time for the return to work. Third, TLICS values did not predict the return to work and radiological or clinical outcomes.

The generally accepted management in stable thoracolumbar and lumbar fractures is conservative treatment, and an external TLSO is recommended according to the level of injury ${ }^{(1-5)}$. There has been debate about the effectiveness of bracing in stable fractures $^{(17)}$. Bailey et al. ${ }^{(18)}$ concluded that using brace in burst fractures with neurologically stable patients did not affect the outcome regarding pain control and function. Therefore, TLSO

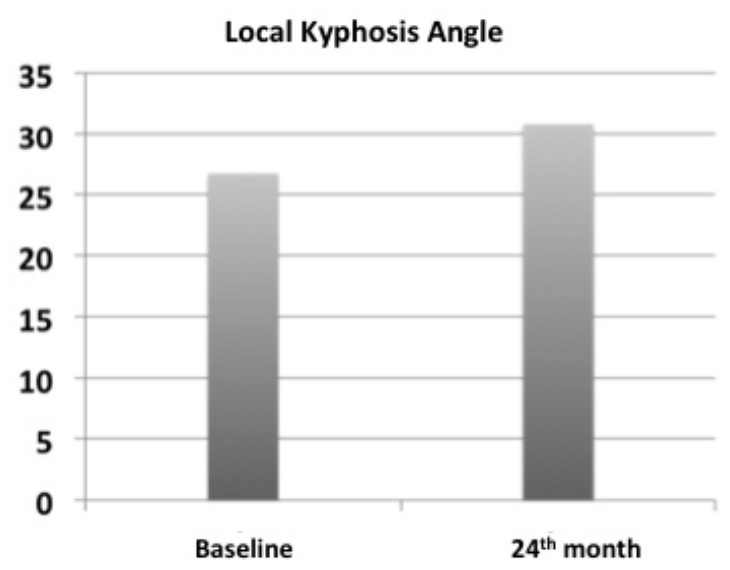

was routinely used for conservative treatment in the present study. According to our results, all patients had improved satisfaction in terms of pain and disability. Herein, we would like to highlight once again that conservative treatment, including TLSO, bed rest, and analgesics, seems to be effective in TLICS 1-3 patients. Our findings were consistent with the literature as regards the effectiveness ${ }^{(1,3-5)}$. However, the TLICS did not predict a return to work. Thus, compatible with the literature ${ }^{(2,9)}$, both ODI and VAS scores correlated with earlier return to work.

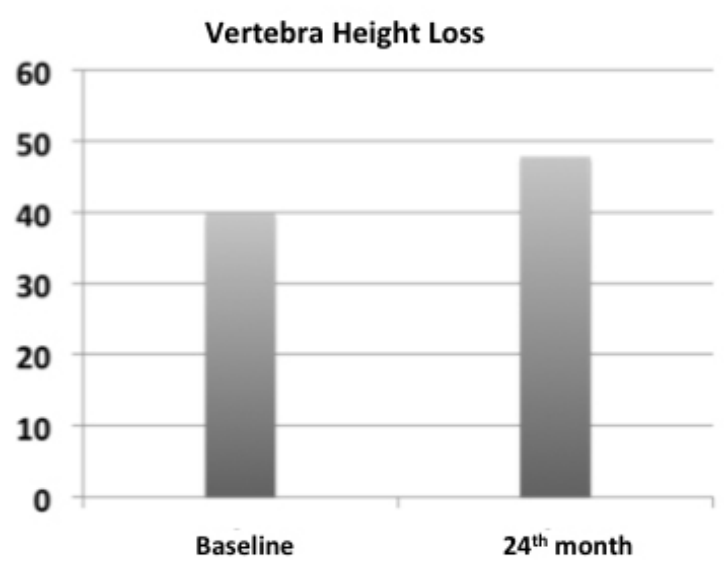

Figure 2. Local kyphosis angle and vertebrae height loss

The mean LKA increased from $26.75 \pm 6.7$ to $30.80 \pm 6.9$ ( $p<0.001$ ). The mean VHL increased from 39.84 \pm 8.7 to 47.81 \pm 8.6 .

LKA: Local kyphotic angle, VHL: Vertebrae height loss

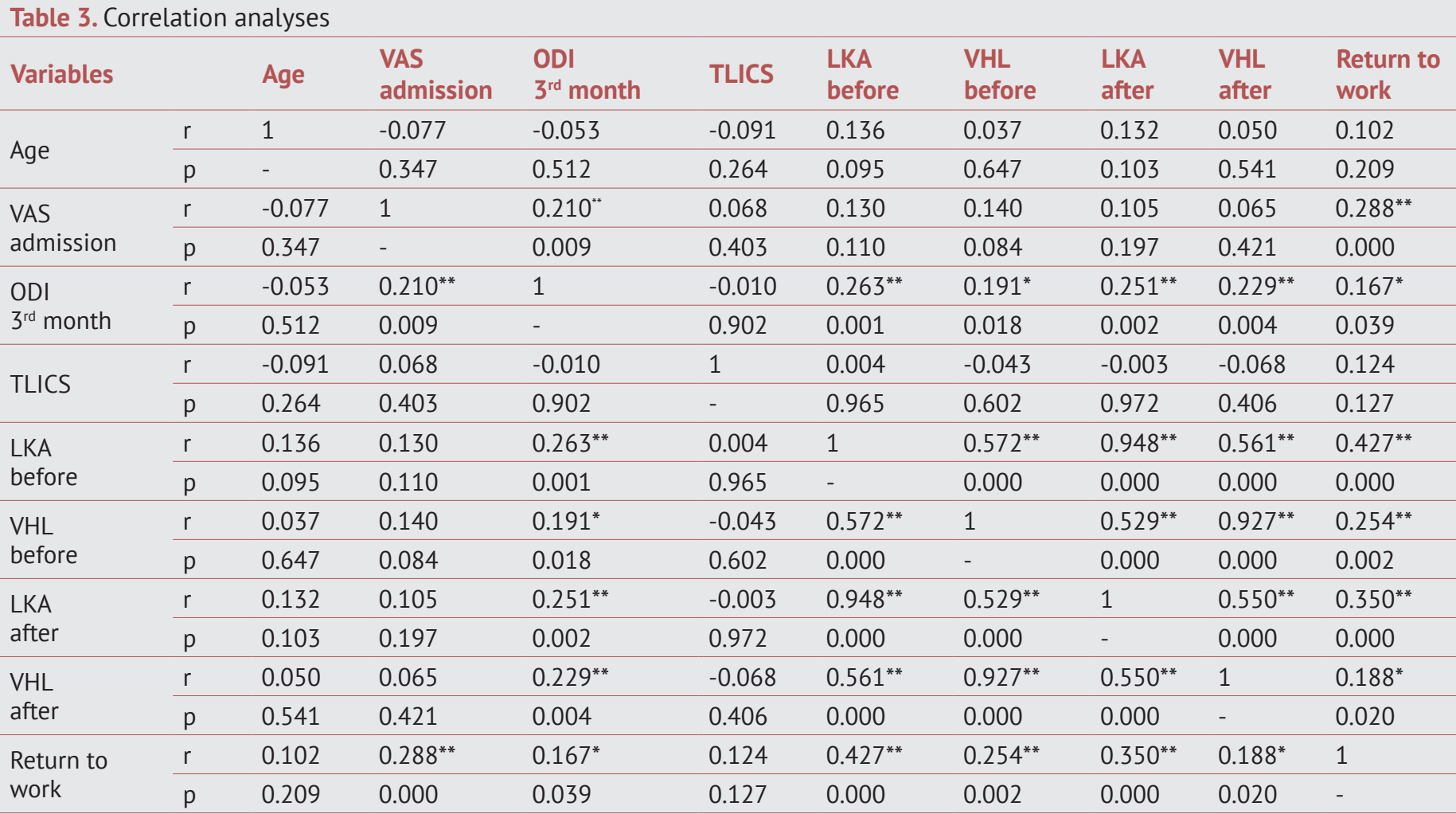

Correlation is significant at the ${ }^{* *} 0.01$ level (2-tailed) or ${ }^{*} 0.05$ level (2-tailed).

VAS: Visual analogue scale, ODI: Oswestry disability index, TLICS: Thoracolumbar injury classification and severity score, LKA: Local kyphotic angle, VHL: Vertebrae height loss 
The time for the return to work is a significant determinant of the efficacy of the management, and this issue was previously studied in several studies in the literature. Wood et al.(19), in a prospective and randomized trial, enrolled 47 patients (24 surgery vs. 23 orthoses) with thoracolumbar burst fractures without neurological deficit. At the final follow-up (minimum two years), there were no statistical differences in terms of return to work between the two groups, with a tendency to better results in the conservative group. Shamji et al. ${ }^{(20)}$ compared bracing with no-bracing groups in their randomized controlled trial whereby there was no difference in terms of LKA and VHL progression or clinical outcomes during the sixth months of the follow-up period. However, the effectiveness of orthosis was investigated and was reported to be a safe method with acceptable functional and radiographic results in the treatment of thoracolumbar fractures ${ }^{(1)}$. Studies also showed that chronic back pain and VHL were associated with patients with thoracolumbar vertebrae fractures ${ }^{(21)}$. In our study, although TLICS 1 to 3 patients improved clinically over time, their radiological parameters, i.e., LKA and VHL, worsened. Besides, the radiological parameters significantly correlated with delayed return to work. Previous reports also reported that TLICS classification had limitations to predict clinical and radiological outcomes in patients who needed surgery for permanent pain or progressive deformity (TLICS score less than 4 points) $)^{(3,6,10,22)}$.

The retrospective design is the main limitation. Although the follow-up period ( $24^{\text {th }}$ months) is acceptable compared with the previous studies, it could be longer. In addition, the absence of a control group or a surgery group is another limitation of this study.

\section{CONCLUSION}

According to the data revealed by the present study, TLICS classification seems to be effective on decision making in the conservative treatment of thoracolumbar and lumbar vertebral fractures, but it would be noteworthy to take into account the clinical and radiological parameters in this classification to predict the treatment period and return to work. Further studies on this matter in prospective designs are awaited.

\section{Ethics}

Ethics Committee Approval: All procedures performed in this study involving human participants were in accordance with the ethical standards of the institutional and/or national research committee and with the 1964 Helsinki declaration and its later amendments or comparable ethical standards (58911/06.2020).

Informed Consent: Informed consent was obtained from the patients.

Peer-review: Internally peer-reviewed.

\section{Authorship Contributions}

Concept: E.K., F.S., O.Ç., A.D., G.P., M.I., H.M.G., Design: E.K., F.S., O.Ç., A.D., G.P., M.I., H.M.G., Data Collection or Processing: E.K., F.S., O.Ç., A.D., G.P., M.I., H.M.G., Analysis or Interpretation: E.K., F.S., O.Ç., A.D., G.P., M.I.., H.M.G., Literature Search: E.K., F.S., O.Ç., A.D., G.P., M.I., H.M.G., Writing: E.K., F.S., O.Ç.,A.D., G.P., M.I., H.M.G. Conflict of Interest: No conflict of interest was declared by the authors.

Financial Disclosure: The authors declared that this study received no financial support.

\section{REFERENCES}

1. Cankaya D, Yilmaz S, Deveci A, Dundar A, Yoldas B, Toprak A, et al. Clinical and radiological outcomes of conservative treatment after stable post-traumatic thoracolumbar fractures in elderly: Is it really best option for all elderly patients? Ann Med Surg (Lond). 2015;4:346-50.

2. Joaquim AF, Ghizoni E, Tedeschi H, Batista UC, Patel AA. Clinical results of patients with thoracolumbar spine trauma treated according to the Thoracolumbar Injury Classification and Severity Score. J Neurosurg Spine. 2014;20:562-7.

3. Hitchon PW, Abode-lyamah K, Dahdaleh NS, Shaffrey C, Noeller J, $\mathrm{He} \mathrm{W}$, et al. Nonoperative management in neurologically intact thoracolumbar burst fractures: clinical and radiographic outcomes. Spine (Phila Pa 1976). 2016;41:483-9.

4. Hitchon PW, He W, Viljoen S, Dahdaleh NS, Kumar R, Noeller J, et al. Predictors of outcome in the non-operative management of thoracolumbar and lumbar burst fractures. $\mathrm{Br} /$ Neurosurg. 2014;28:653-7.

5. Bakhsheshian J, Dahdaleh NS, Fakurnejad S, Scheer JK, Smith ZA. Evidence-based management of traumatic thoracolumbar burst fractures: a systematic review of nonoperative management. Neurosurg Focus. 2014;37:1.

6. Joaquim AF, Patel AA, Schroeder GD, Vaccaro AR. A simplified treatment algorithm for treating thoracic and lumbar spine trauma. J Spinal Cord Med. 2019;42:416-22.

7. Schroeder GD, Harrop JS, Vaccaro AR. Thoracolumbar trauma classification. Neurosurg Clin N Am. 2017;28:23-9.

8. Shen J, Xu L, Zhang B, Hu Z. Risk factors for the failure of spinal burst fractures treated conservatively according to the thoracolumbar injury classification and severity score (tlics): a retrospective cohort trial. PLoS ONE. 2015;10:e0135735.

9. Pneumaticos SG, Karampinas PK, Triantafilopoulos G, Koufos S, Polyzois V, Vlamis J. Evaluation of TLICS for thoracolumbar fractures. Eur Spine J. 2016;25:1123-7.

10. J Joaquim AF, de Almeida Bastos DC, Jorge Torres HH, Patel AA. Thoracolumbar injury classification and injury severity score system: a literature review of its safety. Global Spine J. 2016;6:80-5.

11. Joaquim AF, Daubs MD, Lawrence BD, Brodke DS, Cendes F, Tedeschi $\mathrm{H}$, et al. Retrospective evaluation of the validity of the thoracolumbar injury classification system in 458 consecutively treated patients. Spine J. 2013;13:1760-5.

12. Mattei TA, Hanovnikian J, Dinh DH. Progressive kyphotic deformity in comminuted burst fractures treated non-operatively: the Achilles tendon of the Thoracolumbar Injury Classification and Severity Score (TLICS). Eur Spine J. 2014;23:2255-62.

13. Radcliff K, Su BW, Kepler CK, Rubin T, Shimer AL, Rihn JA et al. Correlation of posterior ligamentous complex injury and neurological injury to loss of vertebral body height, kyphosis, and canal compromise. Spine (Phila Pa 1976). 2012;37:1142-50. 
14. Hur JW, Lee S, Lee JB, Cho TH, Park JY, Suh JK, et al. The limitation of the thoracolumbar injury classification and severity score (tlics) system contemplating with a complicated burst fracture case. J of Advanced Spine Surgery 2014;4:64-8.

15. Yakut E, Düger T, Oksüz C, Yörükan S, Ureten K, Turan D, et al. Validation of the Turkish version of the Oswestry Disability Index for patients with low back pain. Spine (Phila Pa 1976). 2004;29:581-5.

16. Price DD, McGrath PA, Rafii $A$, Buckingham $B$. The validation of visual analogue scales as ratio scale measures for chronic and experimental pain. Pain. 1983; 17:45-56.

17. Joaquim AF, Patel AA. Thoracolumbar spine trauma: Evaluation and surgical decision-making. J Craniovertebr Junction Spine. 2013;4:3-9.

18. Bailey CS, Dvorak MF, Thomas KC, Boyd MC, Paquett S, Kwon BK, et al. Comparison of thoracolumbosacral orthosis and no orthosis for the treatment of thoracolumbar burst fractures: interim analysis of a multicenter randomized clinical equivalence trial. J Neurosurg Spine. 2009;11:295-303
19. Wood K, Buttermann G, Mehbod A, Garvey T, Jhanjee R, Sechriest V. Operative compared with nonoperative treatment of a thoracolumbar burst fracture without neurological deficit. A prospective, randomized study. J Bone Joint Surg Am. 2003;85:773-81.

20. Shamji MF, Roffey DM, Young DK, Reindl R, Wai EK. A pilot evaluation of the role of bracing in stable thoracolumbar burst fractures without neurological deficit. J Spinal Disord Tech. 2014;27:370-5.

21. Park JH, Kang KC, Shin DE, Koh YG, Son JS, Kim BH. Preventive effects of conservative treatment with short-term teriparatide on the progression of vertebral body collapse after osteoporotic vertebral compression fracture. Osteoporos Int. 2014;25:613-8.

22. Azhari S, Azimi P, Shahzadi S, Mohammadi HR, Khayat Kashani HR. Decision-Making Process in Patients with Thoracolumbar and Lumbar Burst Fractures with Thoracolumbar Injury Severity and Classification Score Less than Four. Asian Spine J. 2016;10:136-42. 